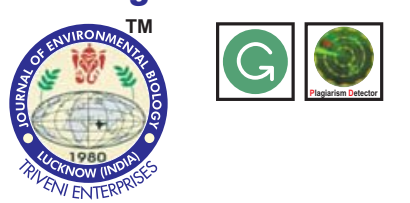

\title{
Galls and host occurrences along a forest gradient in Sierra Juárez, Oaxaca, Mexico
}

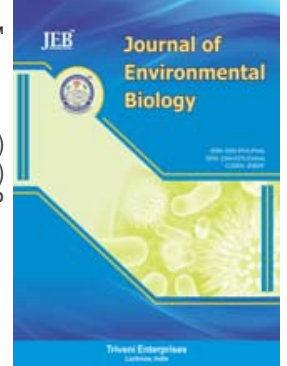

Authors Info

Viviana Rodríguez-Rivera', Cecilia Alfonso-Corrado, Victor AguirreHidalgo', Jorge E. Campos', Crystian $\mathrm{S}$. Venegas-Barrera ${ }^{3}$ and Ricardo Clark-Tapia $^{1 *}$

1 Instituto de Estudios Ambientales, Universidad de la Sierra Juárez, UNSIJ.

Av. Universidad s/n, Ixtlán de Juárez. 68725 Oaxaca, México

¿Laboratorio de Bioquímica MolecularUnidad de Biotecnología y Prototipos (UBIPRO), FES-IZTACALA-UNAM, Av. de los Barrios \# 1, Col. Los Reyes Iztacala, 54000 Tlalnepantla, Estado de México

${ }^{3}$ Instituto Tecnológico de Ciudad Victoria, Blvd. Emilio Portes Gil No 1301, Cd Victoria, Tamaulipas, México. C.P. 870010

*Corresponding Author Email : rclark@unsij.edu.mx

\section{Key words}

Ecological niche,

Forest gradient,

Gall occurence, Oak, Pine,

Regional distribution

Publication Info

Paper received : 18.12.2015

Revised received : 13.04 .2016

Re-revised received : 20.07.2016

Accepted: 12.09 .2016

\begin{abstract}
Aim: This study evaluates the abundance and environmental factors that regulate the regional distribution (hosts and study sites) and specific distribution (microhabitat oviposition) of the galls in the Sierra Juárez, Oaxaca, Mexico.

Methodology: During dry and wet periods, eleven sampling sites, the presence and abundance of galls were examined. . Ecological niche analysis was performed to relate gall niche occurrence/breadths with geographical and climatic gradients at two levels: regional distribution and specific distribution.

Results: Oak had the highest number of galls as compared to pines. Among the oaks, the Quercus section recorded twice the amount of galls $(9 \pm 2.14)$ than the Lobatae section $(4.7 \pm 2.19)$. As for the specific distribution level, over $70 \%$ of the galls were located both at the underside of leaves and at primary stem.

Interpretation: We believe that abundance and distribution of galls and hosts could be associated with climatic factors. It was found that galls are highly sensitive to climatic and geographical changes. Galls are also attached to specific host structures for their survival. Climatic changes and structural disturbance can generate a crisis of co-extinction.
\end{abstract}

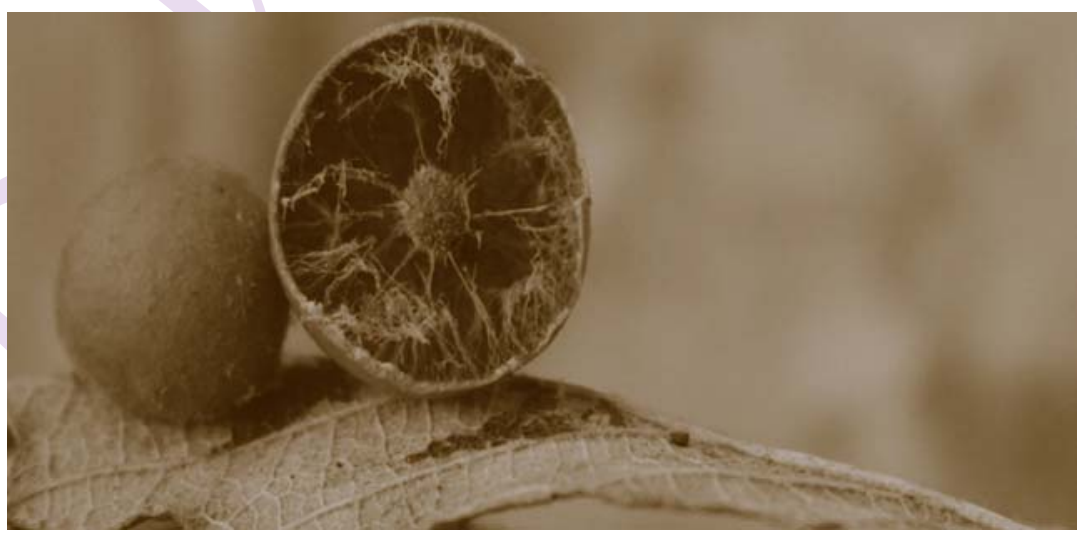




\section{Introduction}

Ecosystem functioning involves complex nonlinear interactions among biotic and abiotic factors that may be affected by climate change processes (Bellard et al., 2012), fragmentation and loss of habitat due to land-use change and development of productive activities, and it can lead to irreversible loss of species (Dornelas, 2010). Numerous studies show that changes in climate (Hódar and Zamora, 2004; Primarck, 2012) affect the abundance and distribution patterns of insects, particularly those which do not have the ability to physiologically regulate their body temperature (Medianero et al., 2010). Additionally, close negative association between diversity and geographical distribution of insect species, with altitudinal changes (Muñoz and AmarilloSuárez, 2010; Clark-Tapia et al., 2013), as well as with processes of disturbance (Dornelas, 2010) have been reported.

Recently, in studies of crisis of biodiversity loss, mutual relationships that lead to co-extinction, or species extinction cascade, have been emphasized (Colwell et al., 2013). The species most sensitive to crisis are the ones that have established some kind of mutual interaction. An example of this type of mutuality is that between host and parasite, where the abundance and distribution of parasites is dependent on the availability of specific hosts (Kamiya et al., 2014). In some cases, the interaction between host and parasite involves a structural change in the morphology of the host, as is the case of galls in plants (Stone and Schönrogge, 2003; Redfern, 2011). At this instance, it may be possible to identify and quantify certain parameters of diversity.

Galls are abnormal growth structures that may be formed in plant tissues due to the parasitic activity of an organism (Redfern et al., 2002). It is estimated there are around 13,000 species of galls-inducing insects. These vary in form and morphological complexity (Stone and Schönrogge, 2003). For instance, wasps in family Cynipidae (Insecta: Hymenoptera) are the most common gall inducers and have very specific host requirements for establishment and development (Abrahamson et al., 1998). In North America, over $80 \%$ of Cynipidae wasps use live oaks (Fagaceae: Quercus) as primary host (Price, 2005). Many of them show high host specificity (Abrahamson et al., 1998; Nieves-Aldrey, 2001; Redfern, 2011). In Oaxaca, 52 of the 150-200 specie of Quercus are present, making Mexico the center of diversity for this genus (Valencia-Ávalos, 2004). Thus, it is likely that there is a high diversity and abundance of gallforming wasps in Oaxaca.

Currently, it is unclear if this relationship between the host and the gall wasp results due to the effect of climate change, change in land use or geographical factors that impact abundance and distribution (Kampichler et al., 2008). However, if the macrohabitat (physical environment), habitat (host species: oaks) and microhabitat (gall) are modified, the conditions for establishment and development of the wasps are affected as well. Previous studies (Gómez-Mendoza and Arriaga, 2007) have shown that climate change processes can have adverse effect on the abundance and distribution of oaks and pines in Mexican territories. Additionally, a cascading effect of greater magnitude may be generated in gall wasps, because these species not only suffer the loss of their specific host, but can also be affected by the continued loss of temperate forests. Although only $16 \%$ of the country is impacted by changes in land use (Velázquez et al., 2002), this can be more dramatic when one considers that, in many cases, silvicultural practices tend to transform monocultural sections of pine forest by removing oaks, which, as previously determined, are of high importance for the gall forming wasps. This study analysed environmental variables that affect the abundance and distribution of galls along a gradient in the temperate forest of Sierra Juárez, Oaxaca using a multivariate analysis 'Outlying Mean Index analysis' (OMI) (Dolédec et al., 2000), in order to assess their sensitivity to climatic, geographical and environmental change.

\section{Materials and Methods}

Study area : The Sierra Juárez is located between $17^{\circ} 19^{\prime} 07^{\prime \prime} \mathrm{N}$ and $96^{\circ} 29^{\prime} 00^{\prime \prime} \mathrm{W}$, in the Ixtlán district, Oaxaca. With elevations that range from 1500 to 3200 masl, its rugged terrain has varied vegetation that is distinguished by the predominance of pine mixed pine-oak, and oak-pine forests. There are 22-recorded species of Quercus (Valencia-Ávalos, 2004) with $70 \%$ oaks of the Quercus section (white) and $30 \%$ of the Lobatae section (red) (Valencia-Ávalos, 2004). These are widely distributed, with one being endemic (Q. macdougallii Martínez), along with14recorded species of Pinus (del Castillo et al., 2004). Of these, $P$. patula y $P$. pseudostrobus are the most important commercial forestry species.

Sampling : To explore the relationship between gall abundance and season, the study was conducted in 11 sampling site during dry season, winter period (December 2011) and during wet season, summer period (July 2012). Two permanently marked transects of $50 \mathrm{~m}$ long and $5 \mathrm{~m}$ wide were established by site. Fig. 1 shows a map of these sites and Table 1 shows their elevation, latitude/longitude coordinates, slope and degree of disturbance. In each transect, the presence and type of gall structures per host was recorded. Simultaneously, each gall (also referred to as structure or morph) was registered as to the specificity of a species, e.g., as formed by only one species of wasp, corroborated with subsequent oviposition.

The hosts were inspected carefully, at several layers, in order to find out structures to the leaf level (upper and underside surface, apex, petiole, midvein, secondary and sublateral vein) and stem level (Stem1: principal stem and Stem2: secondary stem). For taxonomic identification, sample of each host type (e.g. oaks, pines, legumes, etc.) were collected. These activities 


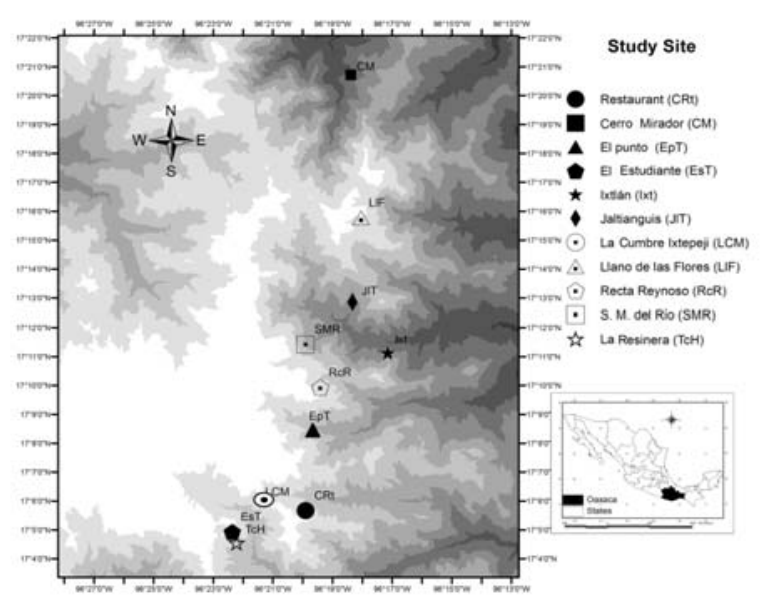

Fig. 1 : Map showing the location of the study sites in the Sierra Juárez, Oaxaca

were performed in the Laboratory of Environmental Studies at the Universidad de la Sierra Juárez.

Statistical analyses : A U Mann-Whitney test was used to determine significant differences in altitude and slope disturbance among sites using the program XLSTAT version 2015.1.01 (XLSTAT, 2015). In addition, the distribution of galls to species level was analysed for specificity to certain hosts, in order to establish whether they were generalists or specialists. Additionally, specific location for each type of gall was recorded. The method of constrained ordination of canonical analysis of principal coordinates (CAP) (Clarke and Gorley, 2006) was used to consider the two study periods as predictive variable for analysing climate effect on the specific distribution.

The occurrence of gall wasps may be subject to environmental factors that affect the geographical distribution of the host, as well as tolerance range of the wasps. With this in mind, the effect of environmental conditions was determined by marginal analysis (OMI) was performed, developed by Doledec et al. (2000). To test the association of environmental variations with the abundance of galls and host species on 11 sites selected, we performed the Outlying Mean Index (OMI), implemented in ADE-4 software (Thioulouse et al., 1997), relating 16 variables with the abundance: three geographical variables (latitude, longitude and altitude) and disturbance level (Table 1) and 12 climatic variables based on monthly average of temperature and precipitation maps of WorldClim database v1.4: Annual Average Temperature (TP), Monthly Average of Minimal Temperature (TMP), Minimal Temperature of Maximal Temperature in warmer Quarter (TMMC), Maximal Temperature of Maximal Temperatures in Colder Quarter (TMPL), Maximal Temperature of Minimal Temperatures in Colder Quarter (TMMF), Temperature Standard Deviation (TDS), Annual minimal precipitation (PM), Annual maximum precipitation (PMM), Monthly precipitation (PMXMX),
Maximum precipitation of driest quarter (PMMC) and Minimum precipitation of wettest quarter (PMMF) (Hijmans et al., 2005).

Monte Carlo test was used to compare the observed marginality of structure versus distribution of 10,000 random permutation values, under null hypothesis that its environment does not affect the gall occurrence. Permutation values lower than 500 were interpreted, as the species marginality index was statistically different from the average environmental conditions available $(p=0.05)$ (Dolédec et al., 2000).

\section{Results and Discussion}

In total, 14 oak species (7 white or Quercus section and 7 red or Lobatae section), four pine species, one Fabaceae and one Asteraceae species were analysed (Table 1) that represented 60 $\%$ of oak species and $29 \%$ of pine species of the Sierra Juárez (del Castillo et al., 2004; Valencia-Ávalos, 2004). Each site registered an average of three oak species $(3.36 \pm 0.87)$ and low occurrence of other species $(0.55 \pm 0.52)$ per site. The species $Q$. crassifolia had the highest frequency, while $Q$. glaucoides, $Q$. obtusata, Q. castanea, Q. trinitatis, Q. laurina, Q. rugosa, P. patula and $P$. pseudostrobus were uncommon species, including Q. macdougallii, which is micro-endemic to Sierra Juárez.

There were higher numbers of galls (121) present in the host species corresponding to the Quercus genus than to the genus Pinus spp. (1), Acacia spp. (1) and species of the Asteraceae family (2). In the Quercus genus, the oak $Q$. glaucoides (23) and Q. obtusata (19), displayed higher presence of galls. Q. scytophylla (3) and Q. urbanii (1), of the Lobatae section, showed least number of gall structures. The results of the study indicated that oaks were the preferred hosts for the family Cynipidae, with $95 \%$ of the galls present in this genus. The preference for oaks matched the results of Nieves-Aldrey (2001) and Redfern (2011), who also reported high specificity for this genus. It has been suggested that the specificity reported for oakwasp galls originates in the phylogenetic relationship between host-parasite (Abrahamson et al., 1998).

These aspects may be linked to high percentage of specialised structures in one species of oak or section. For example, Q. glaucoides was host with the most galls specialists (17), followed by $Q$. obtusata (15), Q. rugosa (12), $Q$. macdougallii (10) and $Q$. liebmannii (9). This feature was also found in two widespread Lobatae section species: $Q$. crassifolia (10) and Q. castanea (9) (Fig. 2). The Quercus section (9 \pm 2.14$)$ presented twice the galls of the Lobatae section $(4.7 \pm 2.19)$. It was noted that widespread species of the Lobatae (Q. castanea and $Q$. crassifolia) section displayed an intermediate amount of morphs specialists, similar to the narrow hosts of the Quercus section.

It has been suggested that gall wasps are unique to each Quercus section, namely, the galls present in the Lobatae 
Table 1: Habitat characteristics and host species of the sites in the Sierra Juárez, Oaxaca

\begin{tabular}{|c|c|c|c|c|c|c|c|c|c|c|c|}
\hline & $\mathrm{CM}$ & LIF & SMR & RcR & Ixtlan & EpT & LCM & CRt & $\mathrm{TcH}$ & EsT & JIT \\
\hline LT & $96^{\circ} 30^{\prime} 4 "$ & $96^{\circ} 30^{\prime} 1^{\prime \prime}$ & 96³3'1" & $96^{\circ} 32^{\prime} 3^{\prime \prime}$ & $96^{\circ} 28^{\prime} 5^{\prime \prime}$ & $96^{\circ} 33^{\prime} 1 "$ & $96^{\circ} 35^{\prime} 5^{\prime \prime}$ & $96^{\circ} 33^{\prime} 2^{\prime \prime}$ & $96^{\circ} 37^{\prime \prime 1 "}$ & $96^{\circ} 37^{\prime} 3^{\prime \prime}$ & $96^{\circ} 30^{\prime \prime} 5^{\prime \prime}$ \\
\hline Lg & $17^{\circ} 34^{\prime} 4^{\prime \prime}$ & $17^{\circ} 26^{\prime} 2^{\prime \prime}$ & $17^{\circ} 19^{\prime} 1 "$ & $17^{\circ} 16^{\prime} 5^{\prime \prime}$ & $17^{\circ} 18^{\prime} 5^{\prime \prime}$ & $17^{\circ} 14^{\prime} 3^{\prime \prime}$ & 17ำ'1" & $17^{\circ} 09^{\prime} 5^{\prime \prime}$ & $17^{\circ} 07^{\prime} 6^{\prime \prime}$ & $17^{\circ} 08^{\prime} 2^{\prime \prime}$ & $17^{\circ} 21^{\prime} 4^{\prime \prime}$ \\
\hline $\mathrm{At}(\mathrm{msl})$ & 2963 & 2896 & 1843 & 2009 & 1960 & 2324 & 2798 & 2622 & 2203 & 1972 & 2385 \\
\hline $\mathrm{Az}\left(\left(^{\circ}\right)\right.$ & 25 & 15 & 10 & 4 & 40 & 30 & 40 & 35 & 30 & 35 & 5 \\
\hline \multirow[t]{4}{*}{$D^{* *}$} & 2 & 2 & 3 & 3 & 2 & 3 & 3 & 2 & 2 & 3 & 3 \\
\hline & Qmc+ & Qpd+ & Qgl+ & Qob+ & Qob+ & Qcs* & Qrg+ & Qrg+ & Qcr* & Qcr* & Qcr* \\
\hline & Qtr* & $\mathrm{Qtr}^{*}$ & Qlb+ & Qgl+ & Qgl+ & Qob+ & Qtr* & Qcr* & Qur* & Qgl+ & Qtr* \\
\hline & Qcr* & Qel $^{*}$ & $\mathrm{QCS}^{*}$ & QCs* & $\mathrm{QCS}^{*}$ & Qcr* & Q.spp+ & Qla* & Plh & Qcr* & Qla* \\
\hline \multirow[t]{4}{*}{ host } & Pppt & & Acc & & Qcr* & & & Qgl+ & Pdg & $\mathrm{Q} \mid b^{*}$ & Qgl+ \\
\hline & & & & & Qsy* & & & Pps & & & Ass \\
\hline & & & & & Pppt & & & & & & \\
\hline & & & & & Pps & & & & & & \\
\hline
\end{tabular}

* Red oak, + white oak, LT: latitude; Lg: Iongitude; At- Altitude; Az-Slope; D- Disturbance. Qmc- Quercus macdougallii; Qtr- Q. trinitatis; Qpd- Q. pedicularis; Qel- Q. elliptica; Qgl- Q. glaucoides; Qlb- Q. liebmanii; Qcs- Q. castanea; Qob- Q. obtusata; Qrg- Q. rugosa; Qsy- Q. sytophylla; Qur-Q. urbanii; Qla-Q. Laurina; Qcr-Q. crssifolia Ppt- Pinus patula; Pps- P. pseudostrogus; Plh- P. leiophylla; Pdg- P. douglasiana; Acc- Acacia spp.; AssAsteraceae; **Disturbance level: 0 -absent of disturbance; 1 - low level (<25\%); 2 -intermediate level (25-50\%); 3- high level $(>50-\%)$

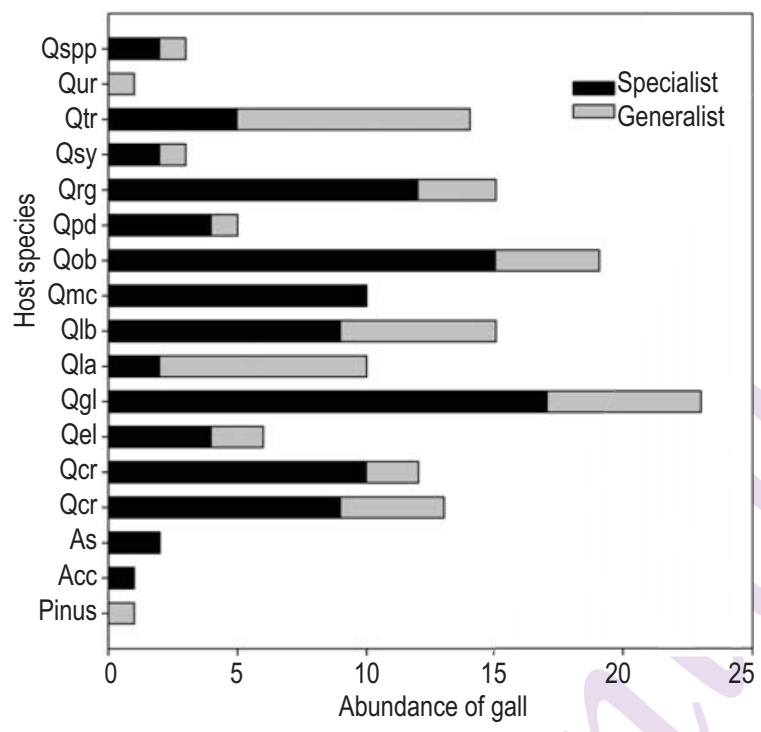

Fig. 2 : Abundance of gall specialists and generalists present in the Sierra Juárez, Oaxaca. See Table 1 for the abbreviation of species

section are not present in the Quercus section (Abrahamson et al., 1998). The results of this study support this suggestion, given the observed higher specificity of structure in the Quercus section. This specificity may be derived from the process of coevolution between oaks and gall species (Stone and Schönrogge, 2003; Price, 2005), hence, the selection to a particular site oviposition (leaves, stems, flowers or fruit) is synchronous with processes of growth, flowering, fruiting or renewal of leaves. These aspects may change due to climatic and geographical processes that determine the distribution of oaks and gall wasp (Medianero et al., 2010; Clark-Tapia et al., 2013).

In addition, it was found that the sampled sites displayed an intermediate to high level of disturbance with an average of $2.44 \pm 0.52$ (Table 1). Disturbance is a causal factor of biodiversity loss (Colwell et al., 2013) that affects the abundance, distribution and species richness, as well as the species interactions (Murray et al., 2008). This study did not show a negative effect on the abundance of galls, despite observed disturbance levels inside the study sites. This finding is consistent with the earlier reports of Medianero et al. (2010) and Clark-Tapia et al. (2013). In highly fragmented places, changes were observed in trophic relationships. For example, there was an increase in density of certain morphs that increase the level of infestation of the host, as well as changes in trophic interactions (such as competition and predation), which can cause direct effects on ecosystem functioning (Ma et al., 2009; Nicholls et al., 2010).

The specific location of the structures showed a preference for the underside of leaf and main stem (Fig. 3); 45 per cent of the galls were found at the leaf level, while $48 \%$ were present at the stem level. More specifically, over $32 \%$ of the galls were located on the underside of the leaves, and $41 \%$ were at the main stem (Stem 1). These two locations of oviposition did not differ significantly; however, there were significant differences in the percentage of galls, in comparison to other sites $\left(x^{2}=32.45, p\right.$ $<0.034$ ) which altogether accounted for less than $10 \%$.

At leaf level it was found that there was a higher average of galls located in the midvein (28.8 \pm 4.1$)$ and secondary vein (12 $\pm 2.92)$, and fewer galls in the sublateral vein $(4.0 \pm 1.7)$. Significant differences in the amount of morphs among the three types of veins $\left(x^{2}=23.8 ; p>0.05\right)$ were also found. The canonical 


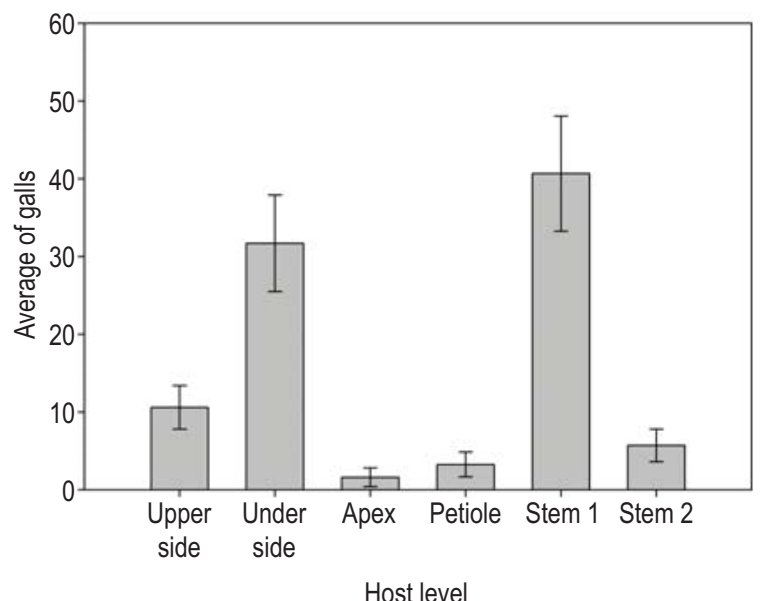

Fig. 3 : Relationship between average of galls per specific location within the host in the Sierra Juárez

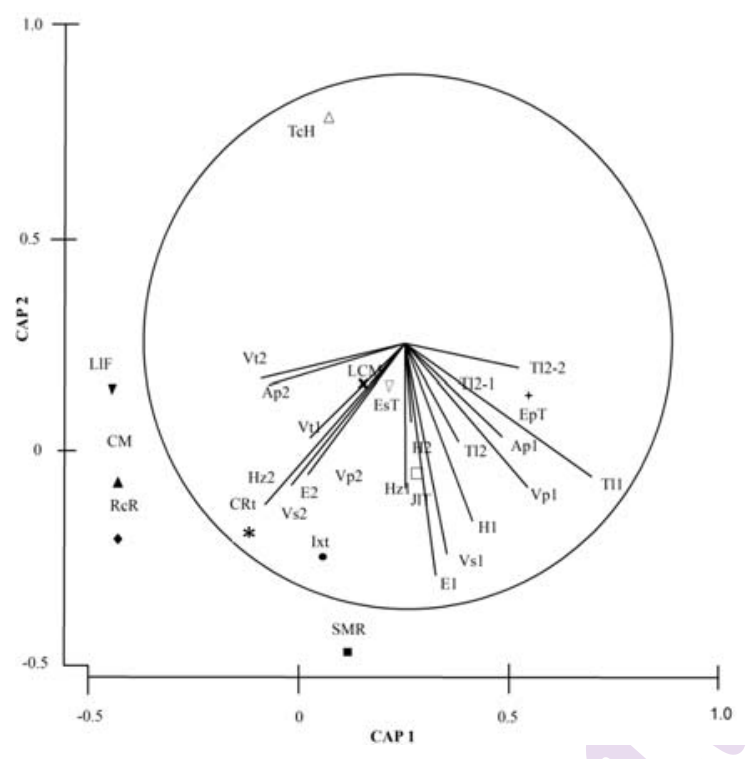

Fig. 4 : Analysis of main canonical coordinates (CAP) in the Sierra Juárez generated by the coefficients of dissimilarity (theta) matrix of abundance and distribution of galls during summer (1) and winter (2). EUnderside surface; H-Upper surface, Ap-apex; Vp-midvein; Vssecondary vein; Vt-Sublateral vein; Tl1-Principal stem and TI2Secondary stem (See Fig. 1 for the abbreviation of sites)

analysis of principal coordinates (CAP) indicated a significant association between the temporal distribution of galls and their specific location within the host (Fig. 4). The squared canonical correlation $\left(\delta^{2}=0.94 ; p=0.001\right)$ was significantly higher, suggesting a good fit of the model, which indicated microhabitat selection preferences for oviposition between the periods.

Medianero et al. (2010) suggested an impact of temperature and humidity on the abundance and distribution of galls between sites; however, they did not encounter differences among the seasons. This overlaps with the results obtained in the current study, since significant differences among the seasons (wet and dry) in the oviposition sites and gall structures were found. This suggests limited tolerance and specific climatic requirements for growth and development of wasps, and synchronization processes with mutual oviposition host-parasite interactions (e.g. periods of flowering, leaf production, growth, etc.), thereby requiring thorough future evaluations.

$\mathrm{OMI}$ analysis indicated a direct effect of environmental variables, such as climate and geography, on the abundance and distribution of galls, marking an ecological pattern for each structures niche; $28 \%$ of the morphs had significant influence of environmental variables (Fig. 5). The galls that did not show significant marginality were those recorded in a small number of ecologically differentiated collecting sites. The rate of change in abundance (inertia) was 15.70 to 49.20 , with an average value of $31.81 \pm 10.26$. The total inertia indicated how environmental variables ecologically separated galls into groups with similar requirements, where morphs $(22,34,61,83,84$, and 102) presented the lowest value of inertia, while a set of eight structures registered the highest value $(41,46,56,88,93,94,95$, and 100).

The structures with high values of marginality index (OMI) was eight with the highest value of inertia (49.20), while lowest values were displayed by the morphs 62,9 and 28 with 2.55 and 4.68 , respectively. The galls with high values of OMl occurred in an atypical habitat, in marginal niches. Low values occurred where galls recorded a wide, rather than marginal distribution (Tsiftsis et al., 2008). On the other hand, $80 \%$ of the structures had low, below average tolerance values $(0.67 \pm 0.13)$, i.e., a niche with either low amplitude or very specialized conditions (Tsiftsis et al., 2008).

The first two axes of OMl analysis explained $67 \%$ of these variances (Fig. 5). The types of galls corresponded differentially to geographical and environmental variables, showing significant correlation to the variables analysed and similar to that obtained by their hosts, which were located in very specific geographical and environmental conditions. The first axis (bottom part) was highly and significantly correlated with maximum precipitation (PMXMX) and latitude (LT), while the second axis (top part) was highly and significantly correlated with TMP, TMMF, PM and PMM.

The position of galls and host species along the first two OMI axes is exhibited in the Fig. 5, where two ecological groups can be clearly separated. The first group (left part of Fig. 5), consisted of morphs and host species associates with wet habitats and higher altitude sites, such as significant morphs (e.g. 10, 16, 38, 45, 64, 65, 77, 81, 91) and host species: $Q$. macdougallii $(\mathrm{Qmc}), \mathrm{Q}$. laurina $(\mathrm{Qla}), \mathrm{Q}$. rugosa $(\mathrm{Qrg}), \mathrm{Q}$. 


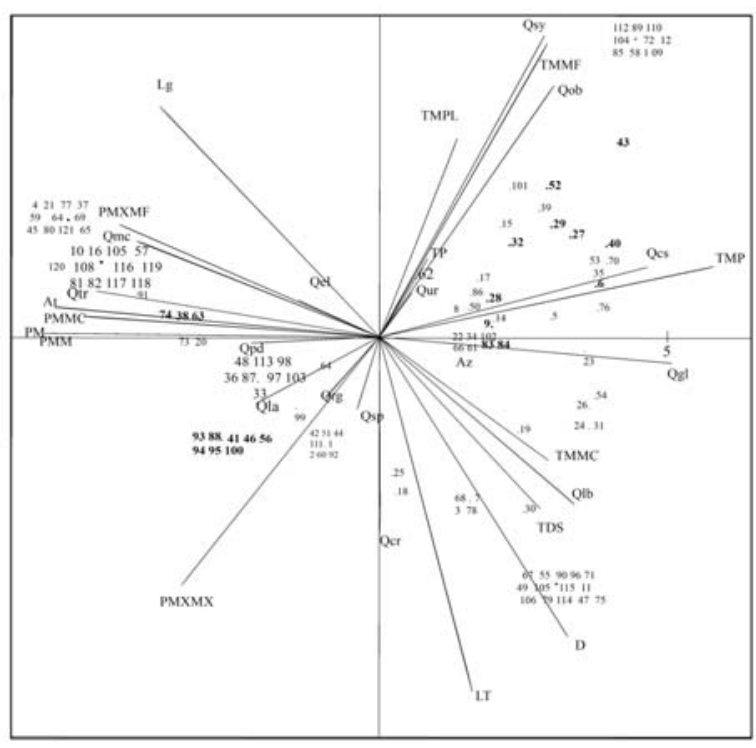

Fig. 5 : Canonical weights of the environmental variables, host species and weighed positions of the galls along the first two axes of $\mathrm{OMI}$ analysis. The length of the arrow describes relative importance of each variable in the analysis, and direction of the arrow indicates among variables of correlations. See Table 1 for abbreviation of variables. Black number indicates morphs with a significant influence of environmental variables

peduncularis (Qpd) and Q. trinitatis (Qtr). The second group (rigth part of Fig. 6) includes galls (e.g. 43, 71, 79, 89, 90, 96 and 112) and host species: Q. glaucoides (Qgl), Q. sytophylla (Qsy), Q. obtusata (Qob) and Q. liebmannii (Qlb) occured in driest habitat at lower and middle altitude.

In the present study, altitude was found to adversely affect the abundance and richness of galls, and similar cases have been reported by Muñoz and Amarillo-Suárez (2010) and Clark-Tapia et al. (2013), because they require great climatic stability, as well as absence of severe extremes, fostered in altitudinal changes. Although latitude and longitude did not have a significant effect on the abundance and distribution of galls and hosts, these variables may affect the presence of the species. Several authors have reported that host plants with wide distribution can accommodate higher phytophagous insects than host with narrow distribution (Strong et al., 1984). Nonetheless, this pattern is not clearly defined in the Sierra Juárez, with Q. crassifolia (being the species most widely distributed and with a smaller number of galls), $Q$. obtusata, Q. castanea and Q. glaucoides having lower distribution, though these had greater distribution than $Q$. scytophylla and Q. peduncularis. Considering that Q. crassifolia requirement was roughly similar to $Q$. rugosa and $Q$. laurina, high percentage of specialist structures to a single host or section contributes to the theory of host-species specificity and coevolution between groups (Stone and Schönrogge, 2003;
Price, 2005).

At national level, researchers have forecasted severe changes in the abundance and distribution of most species of oaks and pines analysed in the present study over the next 50-80 years, due to climate change (Gómez-Mendoza and Arriaga, 2007). Globally, climate change not only affects the abundance and distribution of species (Primarck, 2012, Rao et al., 2013), but also to affect the behavioral of the organisms (Kumar et al., 2013), causing changes in species interactions (Hódar and Zamora, 2004; Lu et al., 2013). This can directly influence mutualistic interactions between host-parasite (Kamiya et al., 2014), due to forced dependence of gall-specific host species, as well as their high climate sensitivity. In this regard, although the current disturbance does not show a direct effect on the abundance of galls, this could change in the future, due to various government programmes acquired by the National Forestry Commission, whose strategy is to increase the amount of forest harvested by more than $94 \%$ over six years, i.e., 2013-2018 (PRONAFOR, 2013-2018). Most communities in the Sierra Juárez practice community forest management, and it acquires forest certification recognition, provided by the Forest Stewardship Council (FSC, 2011). However, implementation of silvicultural systems that consist of clear-cutting, which was designed to transform sections of forest in even-aged stands (e.g. monoculture pine), reduced associated species, including oak, as undesirable ones in the field of forestry. These deemed undesirable species that were eliminated or killed were subsequently discarded, which, in turn promoted drying by cinching (removal of bark, phloem and cambium part).

It is advisable that reduction or exclusion of oak in management zones should be evaluated because it may involve a cascade of species extinction. This is due to high dependence of gall to host, as well as multiple gall-interactions with other species. This high sensitivity to environmental change processes could be used as an ecological indicator of disturbance.

\section{Acknowledgement}

We thank the community authorities of Sierra Juárez and to Susana Valencia for helping us in identifing the oaks species. We are also grateful to Fanny Garvey for providing helpful comments for this manuscript. Financial support was provided by SEP-CONACYT (180790).

\section{References}

Abrahamson, G.W., G. Melika, R. Scrafford and G. Csóka: Gall-inducing insects provide insights into plant systematic relationships. Am. J. Bot., 85, 1159-1165 (1998).

Ashori, A. and N. Kheradpir: Insect Ecology. University of Tehran Publishing (2009).

Bellard, C., C. Bertelsmeier, P. Leadley, W. Thuiller and F. Courchamp: Effects of climate change on the future of biodiversity. Ecol. 
Letters, 15, 365-377 (2012).

Clarke, K.R. and R.N. Gorley: Primer v6: user manual/tutorial. PRIMERE, Plymouth (2006).

Clark-Tapia, R., C. Alfonso-Corrado, J. Campos-Contreras, G. González-Adame, M. Silva-Briano, V. Aguirre Hidalgo and A. Casasola: Abundance and distribution of leaf-shape galls in Quercus resinosa (Fagaceae) in Aguascalientes, Mexico. Polibotánica, 36, 129-145 (2013).

Colwell, R.K., R.R. Dunn and N.C. Harris: Coextinction and persistence of dependent species in a changing world. Ann. Rev. Ecol. Evol. Syst., 43, 183-203 (2013).

del Castillo, R.F., J.A. Pérez de la Rosa, G. Vargas-Amado and R. Rivera-García: Coniferous (Spanish: Coníferas). In: Biodiversity of Oaxaca (Eds.: A.J. García-Mendoza, M.J. Ordóñez y M. BrionesSalas). Instituto de Biología, UNAM-Fondo Oaxaqueño para la Conservación de la Naturaleza-World Wildlife Fund, México, pp. 141-158 (2004).

Dolédec, S., D. Chessel and C. Gimaret-Carpentier: Niche separation in community analysis: a new method. Ecology, 81, 2914-2927 (2000).

Dornelas, M.: Disturbance and change in biodiversity. Philos. Trans. $R$. Soc. Lond. B: Biol., 36, 3719-3727 (2010).

Dunn, R.R., N.C. Harris, R.K. Colwell, L.P. Koh and N.S. Sodhi: The sixth mass coextinction: are most endangered species parasites and mutualists? Proc. Roy. Soc. B: Biol. Sci., 276, 3037-3045 (2009).

Forest Stewardship Council (FSC): Global FSC certificates: type and distribution. FSC, A.C. Bonn, Germany. www.fsc.org. $2^{\text {nd }}$ June 2015. (2011).

Gómez-Mendoza, L. and L. Arriaga: Modelling the effect of climate change on the distribution of oak and pine species of Mexico. Conserv. Biol., 21, 1545-1555 (2007).

Hijmans, R.J., S.E. Cameron, J.L. Parra, P.G. Jones and A. Jarvis: Very high resolution interpolated climate surfaces for global land areas. Int. J. Climatol., 25, 1965-1978 (2005).

Hódar, J.A. and R. Zamora: Herbivory and climatic warming: A mediterranean outbreaking caterpillar attacks a relict, boreal pine species. Biodivers. Conserv., 13, 493-500 (2004).

Kamiya, T., K. O'Dwyer, S. Nakagawa and R. Poulin: Host diversity drives parasite diversity: meta-analytical insights into patterns and causal mechanisms. Ecography, 37, 1-9 (2014).

Kampichler, C.T., K.S. Markus and K. Christian: Effects of 4 years of $\mathrm{CO}_{2}$ enrichment on the abundance of leaf-galls and leaf-mines in mature oaks. Acta Oecol., 34, 39-146 (2008).

Kumar, S., R.K. Pandey, S. Das and V.K. Das: Temperature dependent mortality and behavioral changes in a freshwater mussel Lamellidens marginalis to dimethoate exposure. J. Environ. Biol., 34, 165-170 (2013).

Lewis, O.T. and M.J.M. Seniorardos: Assessing conservation status and trends for the world's butterflies: The Sampled Red List Index approach. J. Insect Conserv., 15, 21-128 (2011).

Lu, X., E. Siemann, X. Shao, H. Wei and J. Ding: Climate warming affects biological invasions by shifting interactions of plants and herbivores. Global Ch. Biol., 19, 2339-2347 (2013).

Ma, W.J., D.R. Yang and Y.Q. Peng: Disturbance effects on community structure of Ficus tinctoria fig wasps in Xishuangbanna, China: implications for the fig/fig wasp mutualism. Insect Sci., 16, 417-424 (2009).

Medianero, E., C.M. Paniagua and G. Castaño-Meneses: Temporal comparison in richness and composition of gall-inducing insects in the rainforest canopy. Rev. Mex. Biodivers., 81, 465-472 (2010).

Muñoz, A. and Á. Amarillo-Suárez: Altitudinal variation in diversity of Arctiidae and Saturniidae (Lepidoptera) in a Colombian cloud forest (Spanish: Variación altitudinal en diversidad de Arctiidae y Saturniidae (Lepidoptera) en un bosque de niebla Colombiano). Rev. Col. Entomol., 36, 292-299 (2010).

Murray, T.E., M. Kuhlmann and S.G Potts: Conservation ecology of bees: Populations, species and communities. Apidologie, 40, 211-236 (2008).

Nieves-Aldrey, J.L.: Hymenoptera, Cynipidae. Fauna Ibérica, Museo Nacional de Ciencias. CSIC. Madrid, Vol. 16, (2001).

Nicholls, J.A., P. Fuentes-Utrilla, A. Hayward, G. Melika, G. Csoka, J.L. Nieves-Aldrey, J. Pujade-Villar, M. Tavakoli, K. Schoenrogge and G.N. Stone: Community impacts of anthropogenic disturbance: Natural enemies exploit multiple routes in pursuit of invading herbivore hosts. BMC Evol. Biol., 10, 322 (2010).

Price, P.W.: Adaptive radiation of gall-inducing insects. Bas. App. Ecol., 6, 413-421 (2005).

Primarck, R.B.: A Primer of Conservation Biology. Sinauer Associates, Inc. USA(2012).

National Forestry Program (Spanish: Programa Nacional Forestal or PRONAFOR) (2013-2018): Forest production and productivity increment in Mexico 2013-2018. National Forestry Commission of Mexico. (Spanish: Incremento a la Producción y Productividad Forestal 2013-2018. Comisión Nacional Forestal or CONAFOR). http://www.conacyt.gob.mx/FondosyApoyos/Sectoriales/Investig acionBasicaAplicada/CONAFOR/Documents/Anexo_C_Estrateg ia_de_incremento_ala\%20_produccion_Fondo_Sectorial.pdf (23td june 2015).

Rao, M.S., K. Srinivas, M. Vanaja, D. Manimanjari, C.A. Rama Rao and B. Ventkateswarlu: Response of multiple generations of semilooper, Achaea janata feeding on castor to elevated $\mathrm{CO}_{2}$. J. Environ. Biol., 34, 877-883 (2013).

Redfern, M.: Plant galls. Harper Collins Publishers. London (2011).

Redfern, M., P. Shirley and M. Bloxham: British plant galls: Identification of galls on plants and fungi. Field Studies, 10, 207-531 (2002).

Stone, G.N. and K. Schönrogge: The adaptive significance of insect gall morphology. Trends Ecol. Evol., 18, 512-522 (2003).

Strong, D.R., J.H. Lawton and T.R.E. Southwood: Insects on plants: community patterns and mechanisms. Blackwell, Oxford London (1984).

Thioulouse, J., D. Chessel, S. Dolédec and J.M. Olivier: ADE4: A multivariate analysis and graphical display software. Statist. Comp., 7, 75-83 (1997).

Tsiftsis, S., I. Tsiripidisa, V. Karagiannakidoua and D. Alifragisb: Niche analysis and conservation of the orchids of East Macedonia (NE Greece). Acta Oecol., 33, 27-35 (2008).

Valencia-Ávalos, S.: Diversity of the Quercus genus (Fagaceae) in Mexico. (Spanish: Diversidad del género Quercus (Fagaceae) en México). Bol. Soc. Bot. Méx., 75, 35-53 (2004).

Velázquez, A., J.F. Mas, J.R. Díaz Gallegos, R. Mayorga Saucedo, P.C. Alcántara, R. Castro, T. Fernández, G. Bocco, E. Ezcurra and J.L. Palacio: Rates and patterns of land-use change in Mexico. (Spanish: Patrones y tasas de cambio de uso del suelo en México). Gaceta Ecol., 62, 21-37 (2002).

XLSTAT: Version 1.01, copyright Addinsoft 1995-2014 http://www.xlstat. $\mathrm{com} /(2015)$. 